\title{
Scrofuloderma Presenting as Recurrent Abscesses - A Case Report
}

\author{
Dr. V. Sudha ${ }^{1}$, Dr. S. Pavithra ${ }^{2}$, Dr. Karrunya. K. J ${ }^{3}$, Dr. Pragna B Dolia ${ }^{4}$ \\ ${ }^{1}$ Professor and HOD, Dept of Dermatology, ACS Medical College and Hospital,Chennai \\ ${ }^{2}$ Senior Resident, Dept of Dermatology, ACS Medical College and Hospital, Chennai \\ ${ }^{3}$ Senior Registrar, Dept of Dermatology, Sundaram Medical Foundation, Chennai \\ ${ }^{4}$ Professor and HOD, Dept of Biochemistry, ACS Medical College and Hospital, Chennai
}

\begin{abstract}
Cutaneous tuberculosis is a relatively uncommon manifestation of tuberculosis.Scrofuloderma is a common form of cutaneous tuberculosis affecting children and young adults.It is a frequent manifestation of cutaneous tuberculosis in India. It represents as direct extension of tuberculosis into the skin from underlying structures like lymph nodes (especially the cervical), bone, lung or joint. It presents as firm,painless,subcutaneous nodules that slowly enlarges and evolves into cold abscesses which suppurates leading to multiple ulcers and draining sinus tracts with undermined edges and healing generally with puckered scars. The most common sites of scrofuloderma are chest, neck and axilla. We are reporting a case of scrofuloderma presenting as recurrent abscesses to emphasize the need of early diagnosis and prompt treatment of the disease in India and countries were tuberculosis is very common.
\end{abstract}

Keywords: Scrofuloderma, Cutaneous Tuberculosis, Recurrent Abscess

Key Messages: Scrofuloderma represents as direct extension of tuberculosis into the skin from underlying structures like lymph nodes (especially the cervical), bone, lung or joint. It presents as firm,painless,subcutaneous nodules that slowly enlarges and evolves into cold abscesses which suppurates leading to multiple ulcers and draining sinus tracts with undermined edges and healing generally with puckered scars ${ }^{3}$.

\section{Introduction}

Cutaneous tuberculosis is a relatively uncommon manifestation of tuberculosis accounting for only 1 to 2 percent of all cases of tuberculosis ${ }^{1}$.Mycobacterium tuberculosis is the major causative organism for cutaneous tuberculosis and rarelyM.bovis. It accounts for $0.1-0.9 \%$ of the total dermatology outpatients in India ${ }^{2}$. There are many types of cutaneous tuberculosis like scrofuloderma, lupus vulgaris, tuberculosis verrucosa cutis, orificial tuberculosis, tuberculous gumma which are seen in our population ${ }^{3}$. Scrofuloderma occurs due to the spread of infection from underlying tuberculosis foci like lymph nodes, bones or joints. It presents as firm, painless, subcutaneous nodules that slowly enlarges and evolves into cold abscesses which suppurates leading to multiple ulcers and draining sinus tracts with undermined edges and healing with puckered scars. The most common sites of scrofuloderma are chest, neck and axilla. The diagnosis is usually by biopsy of the lesion, microbiological demonstration of acid fast bacilli and the newer PCRtechniques. The best treatment for this disease is anti-tubercular drugs (ATT), and people in close contact with the patient such as family members should also undergo testing for tuberculosis ${ }^{4}$.We present here a case report of scrofuloderma presenting as recurrent abscesses to emphasize the need of early diagnosis and prompt treatment of the disease.

\section{Case Report}

A 21year old male, laborer by occupation, resident of Chennai, visited our Dermatology OPD with complaints of recurrent abscesses in the right upper chest, right axilla and dorsum of right hand for the past 4 months that was repeatedly incised for draining the pus in another hospital leading onto multiple ulcers and sinuses formation. Initially the lesion started as a small swelling which gradually increased to painful purulent ulcers on incision and drainage. History of low grade fever was present. There was no history of cough, hemoptysis, and trauma and weight loss. There was also no history of similar complaints in the family nor contact with any tuberculosis patients. He was not a smoker or alcoholic. He belonged to a low socioeconomic status. He was poorly nourished.

Dermatological examination revealed linear ulcers of size $2 \times 1 \mathrm{~cm}$ with bluish undermined edges and purulent discharge over the right side of upper chest and right axilla and swelling with discharging sinus over the dorsum of right hand(Figure 1).Systemic examination was normal.Mantoux test, biopsy from the lesion were done and purulent discharge was sent for GeneXpert for TB diagnosis. The routine lab investigations were within normal limits,HIV test was negative and chest $\mathrm{x}$-ray was normal.Mantoux test was strongly positive $(25 \mathrm{~mm})$. The GeneXpert PCR for TB was positive and Skin biopsy revealed epithelioid cell granuloma in the dermis with Langhan's giant cells and lymphocytes(Figure 4).Clinical picture, Positive Mantoux test, Positive GeneXpert PCR for TB and histopathology were consistent in establishing the diagnosis of scrofuloderma.The patient was started on Category 1 DOTS ATT- antituberculosis treatment [2(HRZE)3/4(HR)3] based on RNTCP programme.The patient was advised protein rich diet. After 2 weeks of ATT, the ulcers started to heal(Figure2)and after 1 month of ATT, the ulcers were

Volume 6 Issue 12, December 2017 


\section{International Journal of Science and Research (IJSR) \\ ISSN (Online): 2319-7064}

Index Copernicus Value (2016): 79.57 | Impact Factor (2015): 6.391

almost completely healing (Figures3).The patient was advised to continue DOTS therapy and come for follow up.

\section{Discussion}

Scrofuloderma also called"Tuberculosis cutis colliquativa" is a common form of cutaneous tuberculosis affecting children and young adults. It is a frequent manifestation of cutaneous tuberculosis in India. It represents as direct extension of tuberculosis into the skin from underlying structures like lymph nodes, bone or joint. It presents as firm, painless, subcutaneous nodules that slowly enlarges and evolves into cold abscesses which suppurates leading to multiple ulcers and draining sinus tracts with undermined edges and healing generally with puckered scar ${ }^{3}$.The most common sites of scrofuloderma are chest, neck and axilla. Tuberculin sensitivity is marked but it has low specificity and hence confirmation can be done by the newer PCR techniques like GeneXpert TB.The histopathological examination is important in the diagnosis of cutaneous tuberculosis. Histopathology shows the presence of characteristic tubercular granulomas with epitheloid cells,Langhan's giant cells and lymphocytes.

Histopathology of cutaneous tuberculosis can mimic many other diseases which produce tuberculoid granuloma ${ }^{5}$.The differential diagnosis of scrofuloderma is bacterial infections, cutaneous leishmaniasis,atypical mycobacterial infections, hidradenitis suppurativa etc.

Various studies have shown that cutaneous TB patients were residing in overcrowded dwellings with severe malnutrition ${ }^{6}$.Malnutrition decreases the immunity of the individual making them more susceptible to cutaneous tuberculosis. Thus the general measures taken should be to treat the malnutrition, treat any concomitant illness causing immunosuppression and giving anti-tuberculosis treatment as per the recommendations of therapy for extrapulmonary $\mathrm{TB}^{2}$

\section{Illustrations}

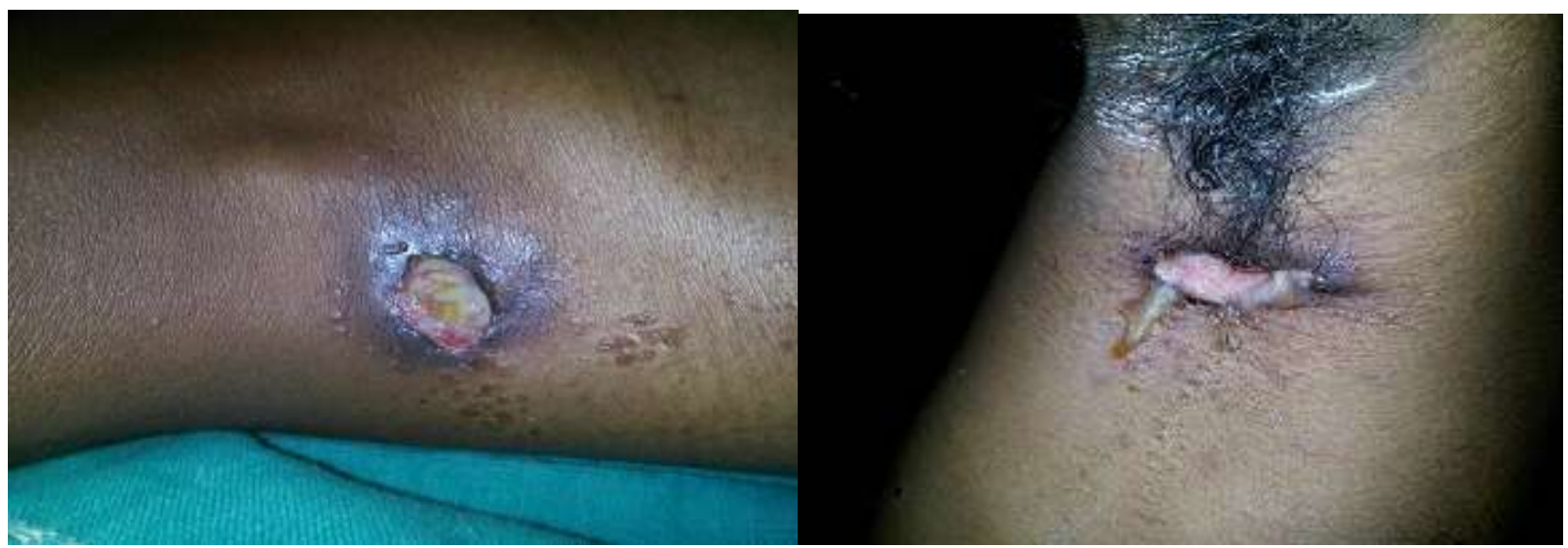

The diagnosis of scrofuloderma in our case was confirmed by the clinical correlation along with strongly positive Mantoux test, positive GeneXpert PCR for TB and histopathology findings. Thus early diagnosis, prompt treatment and good nutrition to improve the immunological status are the key elements to prevent the occurrence of tuberculosis.

\section{Key messages}

1) To confirm cutaneous tuberculosis gene xpert PCR can be done.

2) Cutaneous tuberculosis should be ruled out in recurrent abscess.

\section{References}

[1] James WD, Berger TG, Elston DM. Andrew's disease of the skin. Clinical Dermatology. $11^{\text {th }}$ edtn. Elsevier,2011: p.322.

[2] Sumit Kar et al, "Scrofuloderma - A Case Series from Rural India”, 2011.

[3] Tappeiner G. Tuberculosis and infections with atypical mycobacteria. In: Fitzpatrick's Dermatology in General Medicine. 7th ed. New York: McGraw Hill Medical; 2008. p. 1768. Wolff K, Goldsmith LA, et al editors.

[4] Usma Iftikhar et al, "Scrofuloderma: a common type of cutaneous tuberculosis. A case report", Journal of Pakistan Association of Dermatology 21 (1), 61-65.

[5] Singal A, Sonthalia S. Cutaneous tuberculosis in children: The Indian perspective. Indian $\mathrm{J}$ Dermatol Venereol Leprol 2010;76: 494-503.

[6] Singal A, Pandhi D, Agrawal SK. Multifocal scrofuloderma with disseminated tuberculosis in a severely malnourished child.Pediatr Dermatol 2005; 22: 440-3.

Volume 6 Issue 12, December 2017 
Figure 1: Showing ulcers with purulent discharges and undermined edges present in right side of upper chest and axilla and Sinus present over the dorsum of right hand
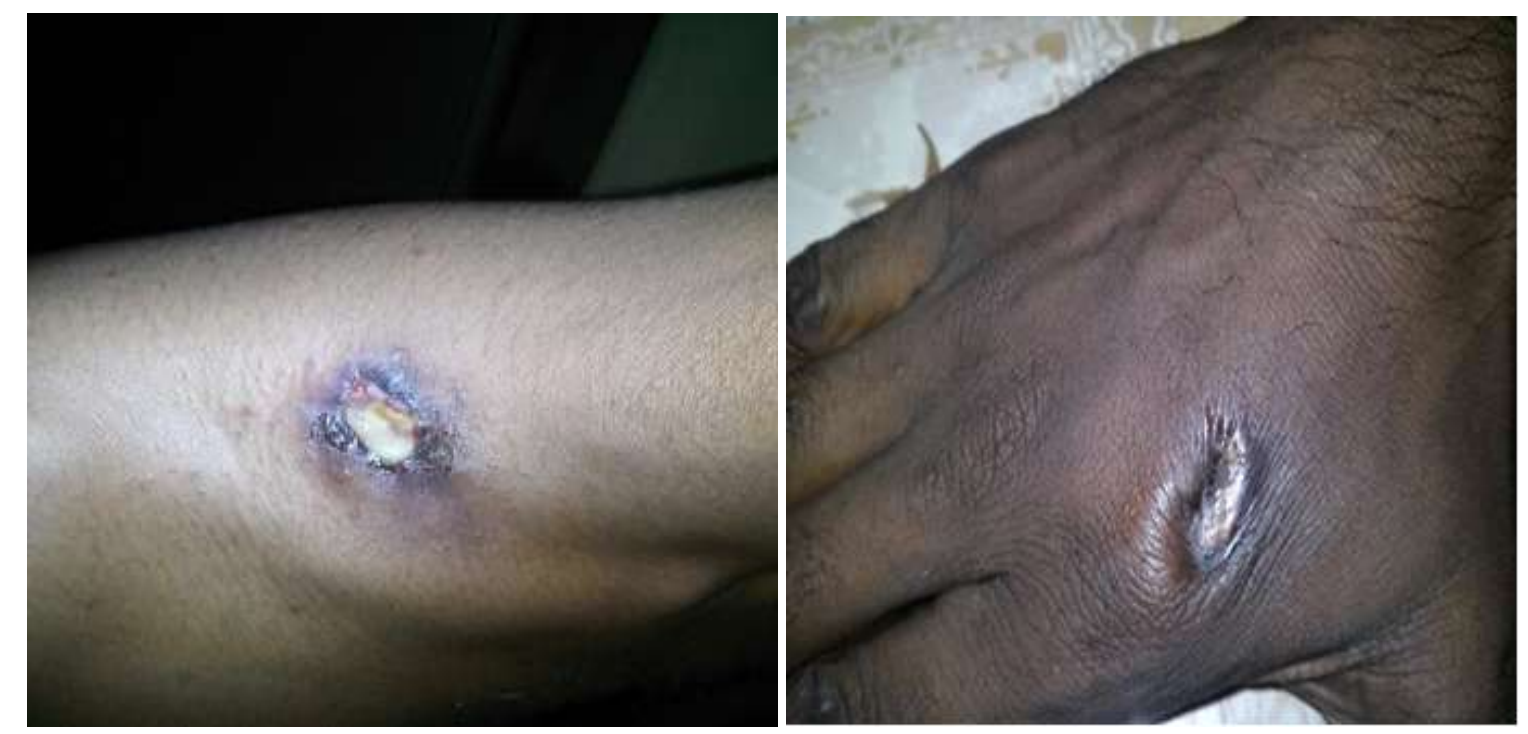

Figure 2: Showing healing of the lesions of right upper chest and dorsum of right hand after 2 weeks of ATT

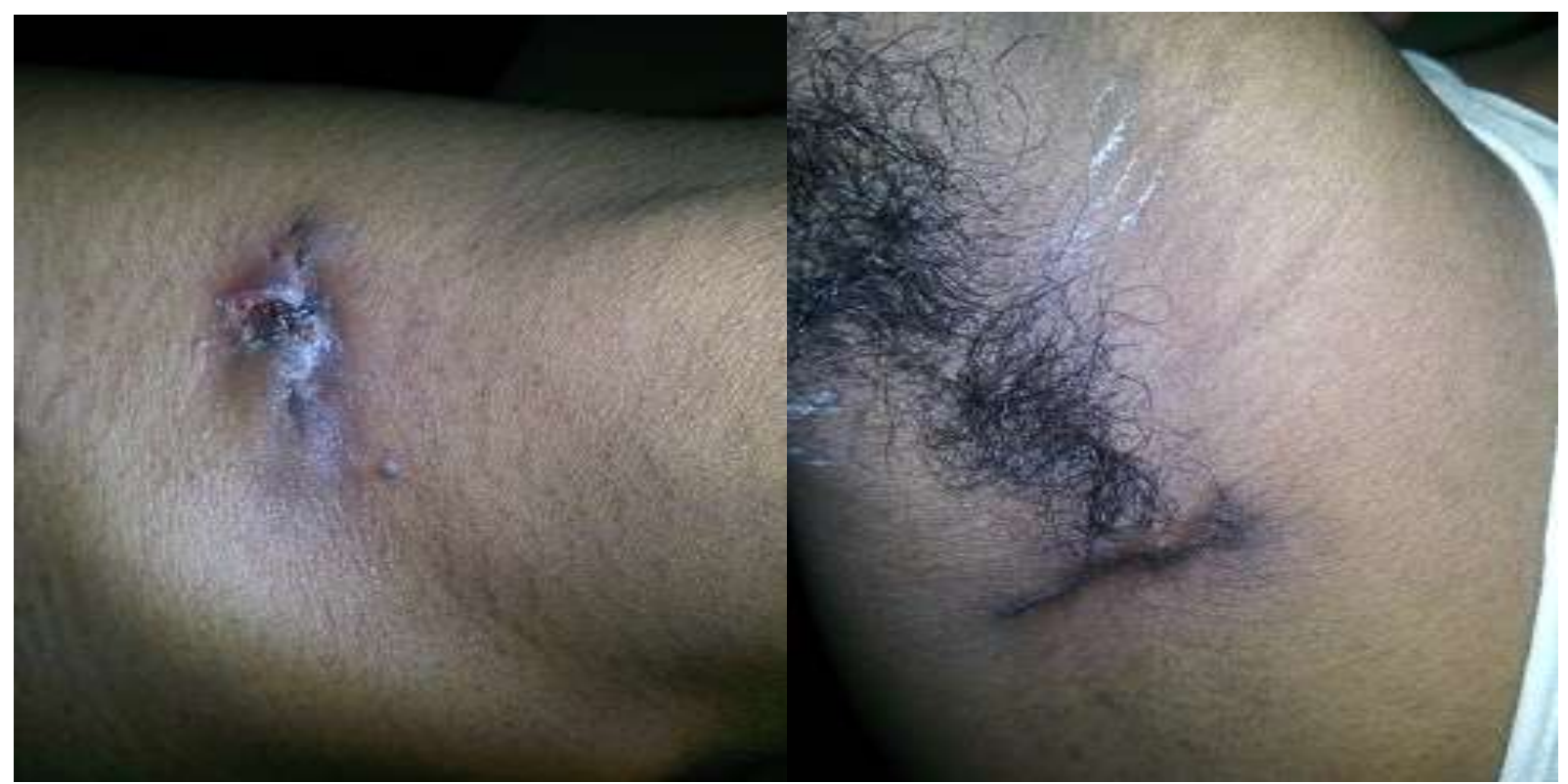

Figure 3: Showing healing of the lesions of right upper chest and axilla after 4 weeks of ATT

Volume 6 Issue 12, December 2017

\author{
www.ijsr.net
}

Licensed Under Creative Commons Attribution CC BY 


\section{International Journal of Science and Research (IJSR)}

ISSN (Online): 2319-7064

Index Copernicus Value (2016): 79.57 | Impact Factor (2015): 6.391

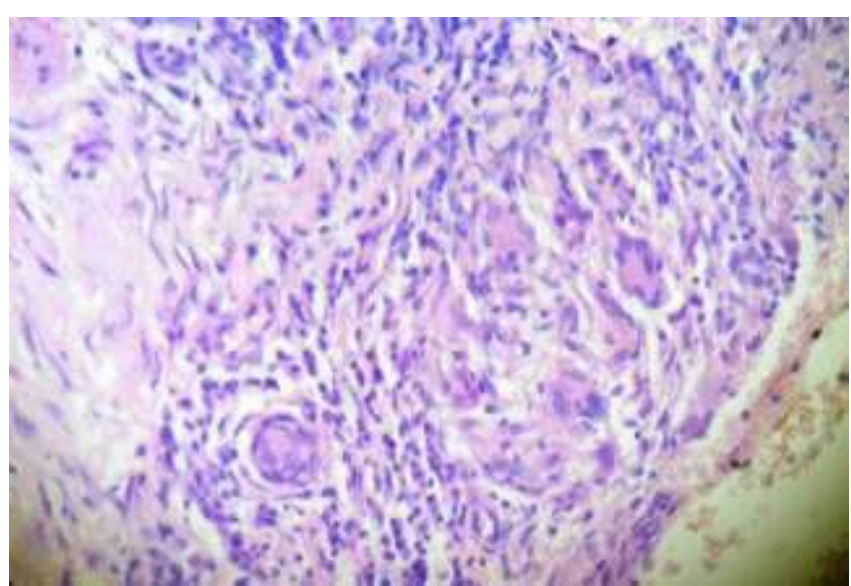

Figure 4: $4 \mathrm{H} / \mathrm{E}$ section $\mathrm{x} 40$ resolution showing tubercular granuloma in dermis with langhan's giant cell

Volume 6 Issue 12, December 2017

www.ijsr.net

Licensed Under Creative Commons Attribution CC BY 